Goldschmidt 2021 Abstract

https://doi.org/10.7185/gold2021.7273

\section{Stable Ca Isotope Fractionation in Cenozoic Marine Mammals: Beyond Biomineralization \& Trophic Positioning}

\author{
COLE M MESSA ${ }^{1}$, KENNETH WW SIMS $^{1}$, SEAN R \\ SCOTT $^{2}$ AND MARK T CLEMENTZ ${ }^{1}$ \\ ${ }^{1}$ University of Wyoming \\ ${ }^{2}$ University of Wisconsin-Madison \\ Presenting Author: cmessa@uwyo.edu
}

Stable $\mathrm{Ca}$ isotopes exhibit mass-dependent fractionation during hard tissue mineralization (i.e., biomineralization), resulting in increasingly lighter $\mathrm{Ca}$ isotope ratios with higher trophic level positions. While this paradigm has proven robust for a multitude of marine food webs, mammal groups present a diverse set of metabolic processes that can potentially fractionate $\mathrm{Ca}$ isotopes, subsequently overprinting the primary $\mathrm{Ca}$ isotope ratio initially preserved within an individual's hard tissue. In this contribution, we present $\mathrm{Ca}$ isotope measurements from an extensive collection of marine mammal hard tissues such as bone and baleen, including from members of the odontocete, sirenia, mysticete and carnivora orders and their associated prey organisms. While most mammal individuals exhibit a predictable decrease in $\mathrm{Ca}$ isotope ratios relative to their prey, mysticetes, specifically bowhead whales, present anomalous $\mathrm{Ca}$ isotope ratios that trend in the opposite direction to that of the established paradigm (Fig. 1). We conclude that this isotopically heavy trend exhibited by the bowhead whales is a result of a catabolic growth spurt that occurs from an age of nine months to five years. During this growth spurt, the bulk skeletal bone density decreases while vital components, such as $\mathrm{Ca}$, are re-directed for rapid construction of both the skull and baleen plates in order to compensate for weaning. Therefore, we argue that the anomalously heavy $\mathrm{Ca}$ isotope ratios preserved within the hard tissue of bowhead whales represents a secondary, massdependent fractionation of $\mathrm{Ca}$ isotopes, resulting in isotopically heavy residual bone ratios and isotopically light baleen ratios for juvenile individuals. Upon completion of the catabolic growth spurt, $\mathrm{Ca}$ isotope ratios preserved within hard tissue returns to isotopically lighter values while the baleen becomes isotopically heavier. Our research suggests that 1) future studies should constrain all metabolic processes capable of fractionating $\mathrm{Ca}$ isotopes within an individual before applying data across entire food webs and 2) illustrates the potential for stable Ca isotopes to reveal details regarding individual species' ontogenesis and ecology.

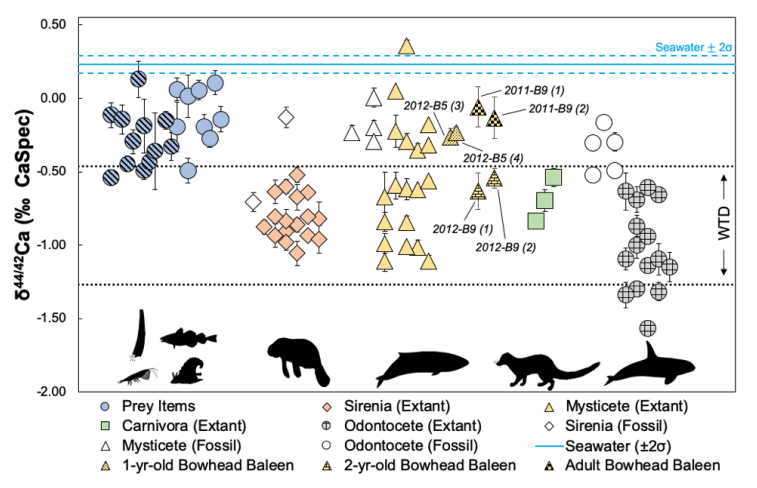

Figure 1: $\delta^{44 / 42} \mathrm{Ca}$ values for marine mammals, separated by order, along with relevant prey (solid blue circles are measured krill, copepods, etc. and striped blue circles are additional fish/crustacean food sources included from literature). Solid symbols represent extant samples. Open symbols represent fossil samples. "WTD" is the window of trophic discrimination ($0.46 \%$ to $-1.27 \% 0$ ). Error
their respective symbol). 